\section{Stand Establishment and Yield Responses to Improved Direct-seeding Methods of Tomatoes}

\author{
Gerald B. Odell ${ }^{1}$, Daniel J. Cantliffe ${ }^{2}$, Herbert H. Bryan ${ }^{3}$, and \\ Peter J. Stoffella ${ }^{4}$ \\ Vegetable Crops Department, Institute of Food and Agricultural \\ Sciences, University of Florida, Gainesville, FL 32611
}

Additional index words. Lycopersicon esculentum, priming, pregermination, gel-mix, plug-mix, soil amendments

\begin{abstract}
Primed, pregerminated, or nontreated 'FloraDade' tomato (Lycopersicon esculentum Mill.) seeds in combination with several soil amendments were evaluated in three experiments for stand establishment characteristics and fresh-market fruit yields. Total percent emergence, seedling shoot weight, and marketable fruit yield were not consistently improved by GrowSorb, gel-mix, plug-mix covers, or mixtures with seeds as compared with a control (soil cover). However, rate of emergence was generally faster for plots containing primed or pregerminated seeds with soil amendments than for plots with a soil cover. Primed or pregerminated seeds emerged faster, and had higher total percent emergence and heavier seedling shoot weights than nontreated seeds, but there was little difference in response between primed and pregerminated seeds. Plants from the primed or pregerminated plots produced earlier (first harvest) marketable fruit than did plants from nontreated seed plots in one of three experiments. Priming or pregermination of tomato seeds resulted in a more consistently improved stand establishment than soil amendments.
\end{abstract}

Methods of priming or osmoconditioning vegetable seeds that have been used to improve germination, emergence, stand establishment, and ultimately early and total yields have been reviewed (Bradford, 1986). Priming tomato seeds has resulted in improved germination or emergence as compared with nontreated seeds (Alvarado et al., 1987; Bussell and Gray, 1976; Georghiou et al., 1982; Ode11 and Cantliffe, 1986; Rumpel and Szudyga, 1978; Wolfe and Sims, 1982). However, emergence differed minimally between primed, pregerminated, or nontreated tomato seeds sown in the field (Ghate and Phatak, 1982). Emergence and earlier yield advantages were maintained for primed (Leskovar and Sims, 1987; Wolfe and Sims, 1982) and pregerminated (Gray et al., 1979; Taylor, 1977) tomato seeds. However, Alvarado et al. (1987) reported that the early

Received for publication 26 Aug. 1991. Accepted for publication 10 June 1992. Florida Agricultural Experiment Station Journal Series no. R-01362. The cost of publishing this paper was defrayed in part by the payment of page charges. Under postal regulations, this paper therefore must be hereby marked advertisement solely to indicate this fact. ${ }^{1}$ Former Graduate Student. Present address: NT Growers, 440 Shelfer St., Quincy, FL 32351. ${ }^{2}$ Professor and Chairman.

${ }^{3}$ Professor, Tropical Research and Education Center, 18905 S.W. 280 St., Homestead, FL 33031. ${ }^{4}$ Professor, Agricultural Research and Education Center, P.O. Box 248, Fort Pierce, FL 34954. emergence from primed tomato seeds was not sufficient to improve early and total yields or soluble solids content of fruits. Field delivery systems such as plug-mix (Hayslip,
1974), fluid drilling (Elliott, 1967), and gelmix (Schultheis et al., 1988a, 1988b) have been used as direct carriers of nontreated, primed, or pregerminated seeds. Bryan and Hayslip (1973) reported that direct seeding tomatoes in a plug-mix "system" resulted in earlier and more uniform yields than covering seeds with soil. The purpose of our investigation was to evaluate seed priming or pregermination in combination with several soil amendments as methods of improving stand establishment and marketable yields of fresh-market tomato.

Experiment 1 was located at the Tropical Research and Education Center, Homestead, Fla., on a Rockdale soil type. Raised beds, $1.0 \mathrm{~m}$ wide, were constructed at $1.8-\mathrm{m}$ centers. Fertilizer was preplant-incorporated into the beds at the rate of $\left(\mathrm{kg} \cdot \mathrm{ha}^{-1}\right) 178 \mathrm{~N}-156 \mathrm{P}-$ $288 \mathrm{~K}$. Soil was fumigated by injecting a methyl bromide-chloropicrin mixture during the bedding operation and covering with black plastic mulch.

Primed $\left(1.5 \% \mathrm{~K}_{3} \mathrm{PO}_{4}+1 \% \mathrm{KNO}_{3}\right.$ at $25 \mathrm{C}$ for 6 days), pregerminated $(48 \mathrm{~h}$ at $25 \mathrm{C}$ in petri dishes), or nontreated 'FloraDade' tomato seeds were sown on 19 Dec. 1984. Soil amendment treatments were plug-mix (peatvermiculite mixture; W.R. Grace, Cambridge, Mass.); Liquagel gel-mix [1:1 (v/v) mix of plug-mix with a $0.75 \%$ solution of Liquagel, hydrophilic starch-acrylate copolymer; Grain Processing, Muscatine, Iowa]; Viterra II gel-mix [1:1 (v/v) mix of plug-mix with a $0.55 \%$ solution of Viterra II gel, a hydrophilic polacrylite polymer; $\mathrm{Ne}$ -
Table 1. Effects of tomato seed treatments and soil amendments on emergence, seedling root weight, and tomato fruit yields (Expt. 1, Homestead, Fla.). ${ }^{\mathrm{z}}$

\begin{tabular}{|c|c|c|c|c|c|}
\hline Soil amendment & $\begin{array}{c}\text { Seed } \\
\text { placement }\end{array}$ & $\begin{array}{c}\text { Emergence } \\
(\%)\end{array}$ & $\begin{array}{l}\text { Shoot wt } \\
\text { (mg) }\end{array}$ & $\begin{array}{c}\text { Marketable } \\
\text { yicld } \\
\left(\mathrm{t} \cdot \mathrm{ha}^{-1}\right)\end{array}$ & $\begin{array}{l}\text { Fruit size } \\
\text { (g/fruit) }\end{array}$ \\
\hline Soil & Covered & 79 & 98 & 8.3 & 109 \\
\hline \multirow[t]{2}{*}{ Plug-mix } & Cuvered & 89 & 104 & 8.9 & 101 \\
\hline & Mixed & 74 & 110 & 7.6 & 105 \\
\hline \multirow[t]{2}{*}{ Liquagel $\mathrm{GM}^{y}$} & Covered & 80 & 138 & 10.1 & 109 \\
\hline & Mixed & 75 & 135 & 9.4 & 106 \\
\hline \multirow[t]{2}{*}{ Viterra II GM } & Covered & 88 & 113 & 7.8 & 105 \\
\hline & Mixed & 79 & 160 & 10.4 & 103 \\
\hline GrowSorb & Covered & 88 & 103 & 8.6 & 109 \\
\hline \multicolumn{6}{|l|}{ Contrasts } \\
\hline \multirow{2}{*}{\multicolumn{2}{|c|}{$\begin{array}{l}\text { Soil vs. others } \\
\text { GrowSorb vs. plug-mix, GM }\end{array}$}} & NS & ** & NS & NS \\
\hline & & NS & ** & NS & $*$ \\
\hline \multicolumn{2}{|l|}{ Plug-mix vs. GM } & NS & ** & NS & NS \\
\hline \multicolumn{2}{|l|}{ Liquagel vs. Viterra II } & NS & NS & NS & NS \\
\hline Cover vs. mixed & & ** & $*$ & NS & NS \\
\hline \multicolumn{6}{|l|}{$\begin{array}{l}\text { Cover vs. mixed } \\
\text { Seed treatment }\end{array}$} \\
\hline \multicolumn{2}{|l|}{ Nontreated } & 80 & 100 & 7.9 & 106 \\
\hline \multicolumn{2}{|l|}{ Primed } & 83 & 128 & 8.8 & 105 \\
\hline \multicolumn{2}{|l|}{ Pregerminated (PG) } & 81 & 134 & 10.1 & 107 \\
\hline \multicolumn{6}{|l|}{ Contrasts } \\
\hline \multirow{2}{*}{\multicolumn{2}{|c|}{$\begin{array}{l}\text { Nontreated vs. primed, PG } \\
\text { PG vs. primed }\end{array}$}} & NS & $* *$ & $*$ & NS \\
\hline & & NS & NS & NS & NS \\
\hline
\end{tabular}

${ }^{\mathrm{z}}$ Planted 19 Dec., harvested 28 Mar.

${ }^{\mathrm{y}} \mathrm{GM}=$ gel-mix.

Ns,,$* *$ Nonsignificant or significant at $P=0.05$ or 0.01 , respectively. 
Table 2. Effects of tomato seed treatments (ST) and soil amendments (SA) on mean days to emergence (MDE) (Expt. 1, Homestead, Fla.). ${ }^{\mathrm{Z}}$

\begin{tabular}{llccc}
\hline \hline & $\begin{array}{c}\text { Seed } \\
\text { SA }\end{array}$ & \multicolumn{3}{c}{ ST } \\
\cline { 3 - 5 } & & & Primed & Pregerminated \\
\hline \multirow{3}{*}{ Soil } & Covered & $7.2^{y}$ & $5 a y s$ \\
Plug-mix & Covered & 7.3 & 5.5 & 6.3 \\
& Mixed & 7.2 & 4.8 & 4.9 \\
Liquagel gel-mix & Covered & 7.2 & 5.0 & 5.1 \\
& Mixed & 6.8 & 4.7 & 5.5 \\
Viterra II gel-mix & Covered & 7.1 & 5.0 & 4.6 \\
\multirow{2}{*}{ GrowSorb } & Mixed & 7.0 & 4.9 & 5.3 \\
& Covered & 7.3 & 5.3 & 4.5 \\
\hline
\end{tabular}

${ }^{\mathrm{z}}$ Planted 19 Dec., harvested 28 Mar.

${ }^{\mathrm{y}} \mathrm{SA} \times \mathrm{ST}$ interaction was significant for MDE. Interaction means were separated by LSD, $P=0.05$. $\mathrm{LSD}_{0.05}$ value is 0.4 day.

pera, Harriman, N.Y.]; and GrowSorb (grade LVM 24/48 calcined montmorillonite clay; Mid Florida Mining, Lowell, Fla.); Rockdale soil served as the control. The plug-mix and gel-mix (60-ml aliquot) were applied as seed covers or with seeds previously suspended, whereas GrowSorb and soil were applied only as covers. A mean of five seeds (hills) were spaced $35 \mathrm{~cm}$ apart in the center of each bed. Each plot consisted of 10 hills. Overhead irrigation was applied immediately after sowing. Emergence counts were made daily for 14 days after sowing (DAS), and a final count was made 21 DAS. Total percent emergence was recorded, and mean days to emergence (MDE) was calculated (Gerson and Honma, 1978) on the basis of emergence during 14 DAS. At 21 DAS, plots were thinned to one plant per hill, the equivalent of 16,000 plants/ha. A random sample of 10 seedlings was cut at the soil surface from each plot, oven-dried at $60 \mathrm{C}$ for 5 days, and weights were recorded.

Insects and diseases were controlled with preventative foliar pesticide applications. Unusually cold weather occurred from 2124 Jan. 1985; therefore, plots were protected by constant sprinkler irrigation. Due to subsequent poor plant growth and development, each plot (8-m section) was manually harvested once on 28 Mar. 1985, 99 DAS. Fruits were graded, and marketable fruit were counted and weighed, and mean fruit size (grams per fruit) was calculated for each plot.

Experiment 2 was located at the Horticultural Research Farm, Univ. of Florida, Gainesville, on fine, sandy flatwoods soil. Raised beds were $7.5 \mathrm{~cm}$ wide and spaced at $1.2-\mathrm{m}$ centers. Fertilizer was incorporated into the beds at the rate of $\left(\mathrm{kg} \cdot \mathrm{ha}^{-1}\right) 162 \mathrm{~N}-94 \mathrm{P}-$ $178 \mathrm{~K}$. A side dressing of $34 \mathrm{~kg} \mathrm{~N}$ and $26 \mathrm{~kg}$ $\mathrm{K} / \mathrm{ha}$ was surface-applied between the beds 65 DAS. Beds were fumigated by injection of 1,2-dichloropropene, 2 weeks before sowing, and then covered with black plastic mulch.

Primed, pregerminated, or nontreated seed treatments were prepared as described in Expt. 1. The soil amendments used were the same as in Expt. 1, with the addition of plug-mix + dry gel (7.5 g Liquagel/liter plug-mix moistened with $70 \mathrm{ml}$ of water), which was applied both as a seed cover and with seeds previously suspended. Hills were spaced 60 $\mathrm{cm}$ apart in the center of each bed, with 10 hills/plot. Overhead irrigation was applied immediately after sowing. At 25 DAS, plots were thinned to one plant per hill, or equivalent to 7400 plants/ha. Plots were harvested on 8 and 18 July 1985, 99 and 109 DAS, respectively. Seeding, harvesting, and data collection procedures were the same as in Expt. 1.

Experiment 3 was located on a commer- cial tomato farm located in Bonita Springs, Fla., on a sandy soil type. Raised beds were $1.0 \mathrm{~m}$ wide, and spaced at $1.8-\mathrm{m}$ centers. Fertilizer was incorporated into the beds at the rate of $\left(\mathrm{kg} \cdot \mathrm{ha}^{-1}\right) 76 \mathrm{~N}-116 \mathrm{P}-62 \mathrm{~K}$, with an additional $226 \mathrm{~kg} \mathrm{~N}$ and $287 \mathrm{~kg} \mathrm{~K} / \mathrm{ha}$ applied in two bands $\approx 30 \mathrm{~cm}$ from the center of the bed. Soil was fumigated by injection of a methyl bromide-chloropicrin mixture during the bedding operation and covered with white on black plastic mulch.

Seed treatments were nontreated and primed, as in Expt. 1. The soil amendment treatments were plug-mix; Viterra NT gel$\operatorname{mix}[1: 1(\mathrm{v} / \mathrm{v})$ mix of plug-mix and $0.55 \%$ solution of gel]; plug-mix + dry Viterra NT gel (5.59 g gel/liter plug-mix); GrowSorb as LVM 24/38; gel-mix GrowSorb (seeds sown in 30-ml aliquots of Viterra gel-mix then covered with $30 \mathrm{ml}$ GrowSorb); and sandy field soil as the control. The soil (control) and GrowSorb were applied as seed covers, while the gel-mix and plug-mix treatments were applied with the seeds mixed in the amendments. Hills were spaced $50 \mathrm{~cm}$ apart in the center of each bed. Overhead irrigation was applied immediately after sowing. At 21 DAS, plots were thinned to one plant per hill, or equivalent to 7400 plants/ha. Plots were harvested on 10 and 19 Dec. 1985, or 94 and 103 DAS, respectively. Seeding, harvesting, and data collection procedures were the same as in Expt. 1.

Statistical procedures. A randomized complete-block design with soil amendment-seed treatment combinations replicated four times was used in each experiment. Percentage of germination was subjected to arcsin transformation before analysis. Analysis of variance was performed on each measured or calculated variable. Main effects of seed treatments or soil amendments were partitioned into orthogonal contrasts. Mean separation of significant seed treatment $\mathrm{x}$ soil amendment interactions were performed by a least significant difference (LSD) test at $P$ $=0.05$.

Daily mean air temperatures for the 14 DAS in Expt. 1 ranged from $27 \mathrm{C}$ (maximum) to $17 \mathrm{C}$ (minimum) and were consid-

Table 3. Effects of tomato seed treatments (ST) and soil amendments (SA) on total percent emergence, mean days to emergence (MDE), and seedling shoot weight (Expt. 2, Gainesville, Fla.). ${ }^{\mathrm{C}}$

\begin{tabular}{|c|c|c|c|c|c|c|c|c|c|c|}
\hline \multirow[b]{3}{*}{$\mathrm{SA}^{y}$} & \multirow[b]{3}{*}{$\begin{array}{c}\text { Sced } \\
\text { placcment }\end{array}$} & \multicolumn{9}{|c|}{ ST } \\
\hline & & \multicolumn{3}{|c|}{ Nontreated } & \multicolumn{3}{|c|}{ Primed } & \multicolumn{3}{|c|}{ Pregerminated } \\
\hline & & $\begin{array}{c}\text { Emerg. } \\
(\%)\end{array}$ & $\begin{array}{l}\text { MDE } \\
\text { (days) }\end{array}$ & $\begin{array}{c}\text { Shoot wt } \\
\text { (mg) }\end{array}$ & $\begin{array}{c}\text { Emerg. } \\
(\%)\end{array}$ & $\begin{array}{c}\text { MDE } \\
\text { (days) }\end{array}$ & $\begin{array}{l}\text { Shoot wt } \\
\text { (mg) }\end{array}$ & $\begin{array}{c}\text { Emerg. } \\
(\%)\end{array}$ & $\begin{array}{l}\text { MDE } \\
\text { (days) }\end{array}$ & $\begin{array}{c}\text { Shoot wt } \\
\text { (mg) }\end{array}$ \\
\hline$\overline{\text { Soil }}$ & Covered & $87^{y}$ & 10.2 & 56 & 91 & 9.8 & 90 & 69 & 9.1 & 85 \\
\hline \multirow{2}{*}{ Plug-mix } & Covered & 57 & 10.2 & 71 & 74 & 9.8 & 82 & 93 & 8.7 & 161 \\
\hline & Mixed & 64 & 9.8 & 85 & 74 & 9.3 & 136 & 76 & 8.8 & 124 \\
\hline \multirow[t]{2}{*}{ Liquagel $\mathrm{GM}^{\mathbf{x}}$} & Covered & 65 & 11.0 & 65 & 75 & 9.0 & 185 & 70 & 9.0 & 128 \\
\hline & Mixed & 56 & 10.0 & 117 & 68 & 8.7 & 175 & 63 & 9.0 & 160 \\
\hline \multirow{2}{*}{ Viterra II GM } & Covered & 94 & 9.9 & 102 & 92 & 8.1 & 213 & 89 & 8.2 & 206 \\
\hline & Mixed & 80 & 9.3 & 130 & 85 & 8.8 & 166 & 81 & 8.3 & 215 \\
\hline GrowSorb & Covered & 93 & 9.3 & 87 & 94 & 8.3 & 167 & 88 & 8.2 & $120^{\circ}$ \\
\hline \multirow{2}{*}{ Plug-mix + DG } & Covered & 55 & 10.6 & 80 & 68 & 10.0 & 92 & 89 & 8.0 & 182 \\
\hline & Mixed & 42 & 10.2 & 76 & 55 & 9.6 & 100 & 46 & 9.8 & 94 \\
\hline
\end{tabular}

${ }^{\text {z}}$ Planted 1 Apr., harvested 8 and 18 July.

${ }^{y}$ SA $\times$ ST interaction was significant for emergence, MDE, and shoot weight. Interaction means were separated by LSD, $P=0.05$. LSD,,, values are $15.1 \%$ for total percent emergence, 1.0 day for MDE, and $55 \mathrm{mg}$ for shoot weight.

${ }^{\mathrm{x}} \mathrm{GM}=$ gel-mix, $\mathrm{DG}=$ dry gel. 
Table 4. Effects of tomato seed treatments and soil amendments on emergence, MDE, and marketable fruit yields (Expt. 3, Bonita Springs, Fla.). ${ }^{\mathrm{z}}$

\begin{tabular}{|c|c|c|c|}
\hline Soil amendment ${ }^{y}$ & $\begin{array}{c}\text { Emergence } \\
(\%)\end{array}$ & $\begin{array}{l}\text { MDE } \\
\text { (days) }\end{array}$ & $\begin{array}{c}\text { Marketable } \\
\text { fruit yield } \\
\left(t \cdot h a^{-1}\right) \\
\end{array}$ \\
\hline Soil & 83 & 5.8 & 33.8 \\
\hline PM & 74 & 4.6 & 33.6 \\
\hline Viterra NT GM & 74 & 4.4 & 33.7 \\
\hline $\mathrm{PM}+\mathrm{DG}$ & 76 & 4.6 & 34.5 \\
\hline $\mathrm{G}$ & 90 & 5.7 & 34.1 \\
\hline $\mathrm{GM}+\mathrm{G}$ & 85 & 4.3 & 35.2 \\
\hline \multicolumn{4}{|l|}{ Contrasts } \\
\hline Soll vs. other & NS $^{y}$ & ** & NS \\
\hline GrowSorb vs. PM, GM, PM + DG, GM $+\mathrm{G}$ & $* *$ & ** & NS \\
\hline $\mathrm{PM}, \mathrm{PM}+\mathrm{DG}$ vs. $\mathrm{GM}, \mathrm{GM}+\mathrm{G}$ & NS & ** & NS \\
\hline PM vs. $P M+D G$ & NS & NS & NS \\
\hline $\mathrm{GM}$ vs. $\mathrm{GM}+\mathrm{G}$ & $*$ & NS & NS \\
\hline \multicolumn{4}{|l|}{ Seed treatment } \\
\hline Nontreated & 78 & 5.8 & 34.2 \\
\hline Primed & 83 & 4.0 & 34.0 \\
\hline Significance & $*$ & * & NS \\
\hline
\end{tabular}

${ }^{\text {zPlanted }} 7$ Sept., harvested 10 and 19 Dec.

${ }^{\mathrm{y}} \mathrm{PM}=$ plug mix, GM = gel-mix; DG = dry gel; $\mathrm{G}=$ GrowSorb.

NS,***Nonsignificant or significant at $P=0.05$ or 0.01 , respectively.

Table 5. Effects of tomato seed treatments and soil amendments on seedling shoot weight (Expt. 3, Bonita Springs, Fla.). ${ }^{\mathrm{z}}$

\begin{tabular}{lcc}
\hline \hline & \multicolumn{2}{c}{ Seed treatment } \\
\cline { 2 - 3 } Soil amendment & $\begin{array}{c}\text { Nontreated } \\
(\mathrm{mg})\end{array}$ & $\begin{array}{c}\text { Primed } \\
(\mathrm{mg})\end{array}$ \\
\hline Soil & $308^{\mathrm{z}}$ & 393 \\
Plug-mix & 453 & 618 \\
Viterra NT gel-mix & 433 & 888 \\
Plug-mix + dry-gel & 480 & 753 \\
GrowSorb & 373 & 430 \\
Gel-mix + GrowSorb & 510 & 898 \\
\hline
\end{tabular}

${ }^{\mathrm{z}}$ Soil amendment $\times$ soil treatment interaction was significant for seedling shoot weight. Interaction means were separated by LSD, $P=0.05$. $\operatorname{LSD}_{0.05}$ value is $157 \mathrm{mg}$ for seedling shoot weight.

ered favorable for tomato germination and emergence. Seed treatments had no significant effect on total percent emergence (Table 1). Soil amendments had no effect on total percent emergence as compared with the soil cover. Total percent emergence for plots with the plug-mix or gel-mix soil amendment was similar to that of GrowSorb-treated plots. Seedlings from primed or pregerminated seeds were heavier than those from nontreated seeds at 21 DAS. Each soil amendment treatment resulted in heavier seedling shoot weights as compared with the soil cover. Gel-mix soil amendment treatments, regardless of seed placement, resulted in a heavier seedling shoot weight than plug-mix treatments. A significant soil amendment $\times$ seed treatment interaction occurred for MDE (Table 2). All soil amendments resulted in faster emergence of primed and pregerminated seeds than the soil cover, except for GrowSorb used as a cover for primed seeds (Table 2). There were no differences between MDE of the soil amendments with nontreated seeds as compared with the soil cover.

Marketable fruit yields and mean fruit size (grams per fruit) from soil amendment plots were not different from the soil cover plots (Table 1). Plots with primed or pregerminated seeds had significantly higher market- able fruit yields than plots with nontreated seeds. Fruit size differences were not significant between seed treatments.

Daily soil surface temperatures averaged 26C day/8C night for 14 DAS during Expt. 2. Odell and Cantliffe (1986) reported that low temperatures can slow the germination rate of 'FloraDade' tomatoes. Seed treatment $x$ soil amendment interactions were significant for total percent emergence, MDE, and seedling shoot weight (Table 3 ). Soil amendment treatments did not increase total percent emergence more than the soil cover for nontreated or primed seeds (Table 3). However, plots with plug-mix, plug-mix + dry gel, Viterra II gel-mix, or GrowSorb covers of pregerminated seeds resulted in higher total percent emergence than the soil cover plots. Soil amendments did not improve MDE over the soil cover for nontreated or pregerminated seeds, except for the plug-mix + dry gel used as a cover for pregerminated seeds. Seeds mixed with Liquagel gel-mix and Viterra II gel-mix or GrowSorb used as covers resulted in a MDE 1 day faster than the soil cover for primed seeds.

Nontreated seeds mixed with Liquagel or Viterra II gel-mix resulted in heavier seedling shoots than did seeds from the soil cover treatment (Table 3). Plants from plots with Liquagel or Viterra II gel-mix used as covers or mixed with seeds had heavier shoot weights than plants in plots with soil cover for primed seeds. Seedling shoot weight was higher in plots with plug-mix used as cover, Liquagel gel-mix mixed with seed, or Viterra II gelmix as cover or mixed with seeds than in the plots with soil cover for pregerminated seeds.

Marketable fruit yield and mean fruit size were not significantly different between soil amendments or seed treatments (data not presented). However, in the second harvest, plots with primed and pregerminated seeds had a higher percentage of fruit with red pigmentation (breaker full red) than plots with nontreated seeds (data not presented).

Differences in stand establishment or marketable fruit yield were minimal between primed and pregerminated seed in Expts. 1 and 2 (Tables 1-3); therefore, seed treatments in Expt. 3 were reduced to primed or nontreated and planted in a commercial field. Daily air temperature averaged 33C day/22C night for 14 DAS during Expt. 3. Primed seeds had a higher total percent emergence and faster MDE than nontreated seeds (Table 4). Soil amendment treatments did not increase total percent emergence compared with the soil cover. However, MDE was $\approx 1$ day faster in plots with soil amendments compared with the soil cover, except for the GrowSorb treatment (Table 4). The soil amendment $\times$ seed treatment interaction was significant for seedling shoot weight (Table 5). Seedling shoots for primed seeds in the soil amendment plots, except for GrowSorb, were heavier than in the plot with soil cover. However, only the gel-mix plus GrowSorb and plug mix + dry gel soil amendments improved seedling shoot weight on nontreated seeds as compared with the soil cover.

Although total percent emergence was generally not increased in soil amendment plots as compared with the soil cover, MDE was 1 to 2 days faster in the soil amendment plots than in the soil cover plot. Also, seedling shoot weights were generally higher from plants sown with soil amendment coverings than with a soil cover.

Experiments 1 and 2 were conducted in moderate to cool soils. Perkins-Veazie and Cantliffe (1989) reported that stand establishment of cabbage (Brassica oleracea, Capitafa Group) was not improved by priming or pregerminating seeds in combination with various soil amendments in moderate or cool fields. However, they also reported that under high soil temperatures pregerminated cabbage seeds sown with Liquagel or Laponite gels resulted in incomplete stands, whereas plug-mix or GrowSorb improved stands. Schultheis et al. (1988a) reported that sowing pregerminated bell pepper (Capsicum annuum L.) seeds in Liquagel gel-mix resulted in faster emergence, uniform plant stands, and earlier and more uniform anthesis than sowing nongerminated seeds.

The present work with tomato expands on the above-reported results. Overall, germination rate and uniformity were enhanced by sowing primed or pregerminated tomato seeds. Under most soil environmental conditions, seed treatment or soil amendment did not improve total emergence of tomato, even in the extremely warm soils of the fall experiment at Bonita Springs. In all three experiments, field cultural conditions (tillage, moisture, etc.) were ideal, and emergence was generally high among all treatments. Improved stands through improved field emergence yields were observed only at Homestead. Cold, cloudy weather occurred during midseason plant growth at this location, and early uniform stand establishment of the seedings led to better growth during this period of environmental stress.

\section{Literature Cited}

Alvarado, A.D., K.J. Bradford, and J.A. Hewitt. 1987. Osmotic priming of tomato seeds: Effects 
on germination field emergence, seedling growth and fruit yields. J. Amer. Soc. Hort. Sci. 112:427-432.

Bradford, K.J. 1986. Manipulation of seed water relations via osmotic priming to improve germination under stress conditions. HortScience $21: 1105-1112$

Bryan, H.H. and N.C. Hayslip. 1973. Plug mix seeding of tomatoes on rockdale soils. Univ. of Fla. Res. Rpt. SB73-7.

Busscll, W.T. and D. Gray. 1976. Effects of presowing seed treatments and temperatures on tomato seed germination and seedling emergence. Scicntia Hort. 5:101-109.

Elliott, J.G. 1967. The sowing of seeds in aqueous fluid. 2nd Annu. Rpt., Weed Res. Org., Begbroke Hill. Oxford. p. 31-32.

Georghiou, K., C.A. Thanos, T.P. Tafas, and K. Mitrakos. 1982. Tomato seed germination. Osmotic pretreatment and full red inhibition. J. Expt. Bot. 33:1068-1075.

Gcrson, R. and S. Honma. 1978. Emergence response of the pepper at low soil tcmpcrature. Euphytica 27:151-156.
Ghate, S.R. and S.C. Phatak. 1982. Performance of tomato and pepper seeds germinated before planting. J. Amer. Soc. Hort. Sci. 107:908911.

Gray, D.J., R.D. Steckel, and J.A. Ward. 1979. The effects of fluid sowing pre-germinated seeds and transplanting on emergence, growth and yield of outdoor bush tomatoes. J. Agr. Sci., Cambridge 93:223-233.

Hayslip, N.C. 1974. Plug-mix seeding developments in Florida. Proc. Fla. State Hort. Soc. 86:179-183.

Leskovar, D.I. and W.L. Sims. 1987. Emergence and yield of tomato (Lycopersicon esculentum Mill.) in response to presowing treatments. Acta Hort. 200:145-152.

Odcll, G.B. and D.J. Cantliffe. 1986. Seed priming procedures and the effect of subsequent storage on the germination of fresh market tomato seeds. Proc. Fla. State Hort. Soc. 99:303306.

Perkins-Veazie, P.M. and D.J. Cantliffe. 1989. Improved stand establishment of direct-seeded cabbage with seed covers. J. Amer. Soc. Hort. Sci. 114:36-39.

Rumpel, J. and I. Szudyga. 1978. The influence of prc-sowing seed treatments on germination or emergence of tomato 'New Yorker' at low temperatures. Scientia Hort. 9:119-125.

Schultheis, J.R., D.J. Cantliffc, H.H. Bryan, and P.J. Stoffclla. 1988a. Planting methods to improve stand establishment, uniformity, and earliness to flower in bell pepper. J. Amer. Soc. Hort. Sci. 113:331-335.

Schultheis, J.R., D.J. Cantliffe, H.H. Bryan, and P.J. Stoffella. 1988b. Improvement of plant cstablishment in bell pepper with a gel-mix planting medium. J. Amer. Soc. Hort. Sci. 113:546552.

Taylor, A.G. 1977. Comparative performance of pregerminatcd, high moisture content and dry vegetable seed in greenhousc and field studies. J. Seed Technol. 2:52-61.

Wolfe, D.W. and W.L. Sims. 1982. Effects of osmoconditioning and fluid drilling of tomato seed on emergence rate and final yield. HortScience 17:936-937. 